\title{
Interactive comment on "Radiocarbon dating of alpine ice cores with the dissolved organic carbon (DOC) fraction" by Ling Fang et al.
}

Anonymous Referee \#2

Received and published: 10 October 2020

\section{Review of Fang et al}

This manuscript presents the first results of a technique that utilizes $14 \mathrm{C}$ of DOC to date alpine ice cores. The basal sections of alpine ice cores are difficult to date because of high degree of ice thinning (making layer counting impossible) and complex ice flow. The approach used in this study is very analytically challenging, and in my opinion the method has been carefully developed and tested. The analytical precision on the $\mathrm{F} 14 \mathrm{C}$ values is impressive considering the small sample sizes. Considering that this approach requires smaller ice samples $(\approx 250 \mathrm{~g})$ than the earlier approach developed by the same group that uses insoluble organic carbon, this now seems like the most promising technique for dating alpine basal ice. Overall, I think that this is an exciting study that is in principle well suited for The Cryosphere. However, I think the study and 
manuscript also have some weaknesses that should be addressed.

Major Comments:

One of the major goals of this study / manuscript is validation of the 14C-DOC technique. In my opinion the manuscript doesn't fully achieve this. The main approach for this evaluation is comparison with the WIOC-14C results. But those results seem to be affected (to varying degrees) by $14 \mathrm{C}$ interference from carbonate dust in the samples. Are the authors able to measure a few samples from a layer-counted Greenland ice core, for example, to provide a more robust validation? I realize that this may be difficult, both because of lower DOC concentrations and ice availability, but perhaps a core from a coastal ice cap such as Renland could be a good target?

I think it would be valuable to provide a more complete analysis of the overall dating uncertainties. If $14 \mathrm{C}-\mathrm{WIOC}$ is the benchmark measurement that is being used for validation of 14C-DOC, then the uncertainties in the 14C-DOC ages need to fully reflect the uncertainties associated with us 14C-WIOC (see more on this below). Alternatively, if the authors consider 14C-DOC to be an inherently superior approach (as compared to $14 \mathrm{C}-$ WIOC), then a more clear argument needs to be made for this.

I think the uncertainties associated with the correction for carbonate dust (for WIOC14C) need to be more thoroughly considered. The authors provide some helpful discussion of this in the supplement (starting on line 33), but l'm not convinced that the uncertainties are fully accounted for. For example, it seems to me that F14Ccarb could in principle range from 0 to 1 depending on the source of the carbonate. One could imagine a situation with seasonally-drying lakes in arid regions, for example, where the carbonate dust at the surface would be close to modern in its $14 \mathrm{C}$ signature. The $\mathrm{C} /$ Ca ratio in dust derived from dolomite would be twice as large as what is being used in Supplement equation 2. The effect of these additional uncertainties may be visible in figure $3 b$ - while the correction makes the Chongce samples look more reasonable, two of the Belukha samples now fall off the trend. 
Minor Comments: Line 73. For water-soluble organics sourced from biomass burning, there may be an age offset due to the older ages of the burned material. While this is probably small compared to the measurement uncertainties, it would still be worth mentioning briefly. Similar comment for organics sourced from oceanic emissions (affected by ocean radiocarbon reservoir effect).

Line 191 . Why is the Libby half-life of $14 \mathrm{C}$ being used here instead of the more accurate value of $5730 \mathrm{yrs}$ ?

Figure $3 b$ legend. Use a label that's more descriptive than "corr" for the corrected data; perhaps just say "corrected results"

Line 278. "As described in Section 3.2, no significant difference between F14C of DOC and WIOC was observed for the ice samples from Colle Gnifetti, Belukha and SLNS (Figure 3)." This is incorrect. Based on the figure, the differences seem significant at the 1-sigma level for several samples, and at the 2-sigma level for at least 1 sample.

Table 5 / Figure 4 and associated text. I think that the discussion of the limitations of this comparison to the previous age estimates should be expanded to provide some more detail / caveats associated with the comparison. For example, how close were the CG and Chongce cores to each other / do we even expect the basal ice to be of similar age? Is the comparison at Belukha still meaningful given the different core locations?

While I think that the authors' conclusion that there is no evidence that in situ $14 \mathrm{C}$ is affecting the 14C-DOC measurements is likely correct, the authors should do a better job of supporting this conclusion. For example, how can you be certain that the higher 14C-DOC as compared to $14 \mathrm{C}-$ WIOC in most samples is not due to in situ 14C? The largest offsets are observed at Chongce, which has the highest altitude and therefore should in principle have the highest in situ 14C production rates. 